\title{
CORRIGENDUM
}

\section{Psychophysical analysis of contrast processing segregated into magnocellular and parvocellular systems in asymptomatic carriers of 11778 Leber's hereditary optic neuropathy}

M. GUALTIERI, ${ }^{1,2}$ M. BANDEIRA, ${ }^{1,2}$ R.D. HAMER, ${ }^{2,8}$ M.E. COSTA, ${ }^{1,2}$ A.G.F. OLIVEIRA, ${ }^{1,2}$

A.L.A. MOURA, ${ }^{1,2}$ F. SADUN ${ }^{3}$ A.M. DE NEGRI, ${ }^{4}$ A. BEREZOVSKY,${ }^{5}$ S.R. SALOMÃO,${ }^{5}$ V. CARELLI, ${ }^{6}$

A.A. SADUN, ${ }^{7}$ AND D.F. VENTURA ${ }^{1,2}$

${ }^{1}$ Departmento de Psicologia Experimental, Universidade de São Paulo, São Paulo, Brasil

${ }^{2}$ Centro de Neurociências e Comportamento, Universidade de São Paulo, São Paulo, Brasil

${ }^{3}$ Ospedale S. Giovanni Evangelista, Tivoli, Italy

${ }^{4}$ Azienda Ospedaliera S. Camillo-Forlanini, Roma, Italy

${ }^{5}$ Departmento de Oftalmologia, Universidade Federal de São Paulo, São Paulo, Brasil

${ }^{6}$ Department of Neurology, University of Bologna, Bologna, Italy

${ }^{7}$ Doheny Eye Institute, Keck-USC School of Medicine, Los Angeles, California

${ }^{8}$ Smith-Kettlewell Eye Research Institute, San Francisco, California

(This article appeared in Volume 25, Number 3, 2008, pp. 469-474).

The abscissa in Fig. 1 (p. 471) was labeled in units of $\mathrm{cd} / \mathrm{m}^{2}$. The correct units are trolands (Td), and a new Fig. 1, so labeled, is shown below.

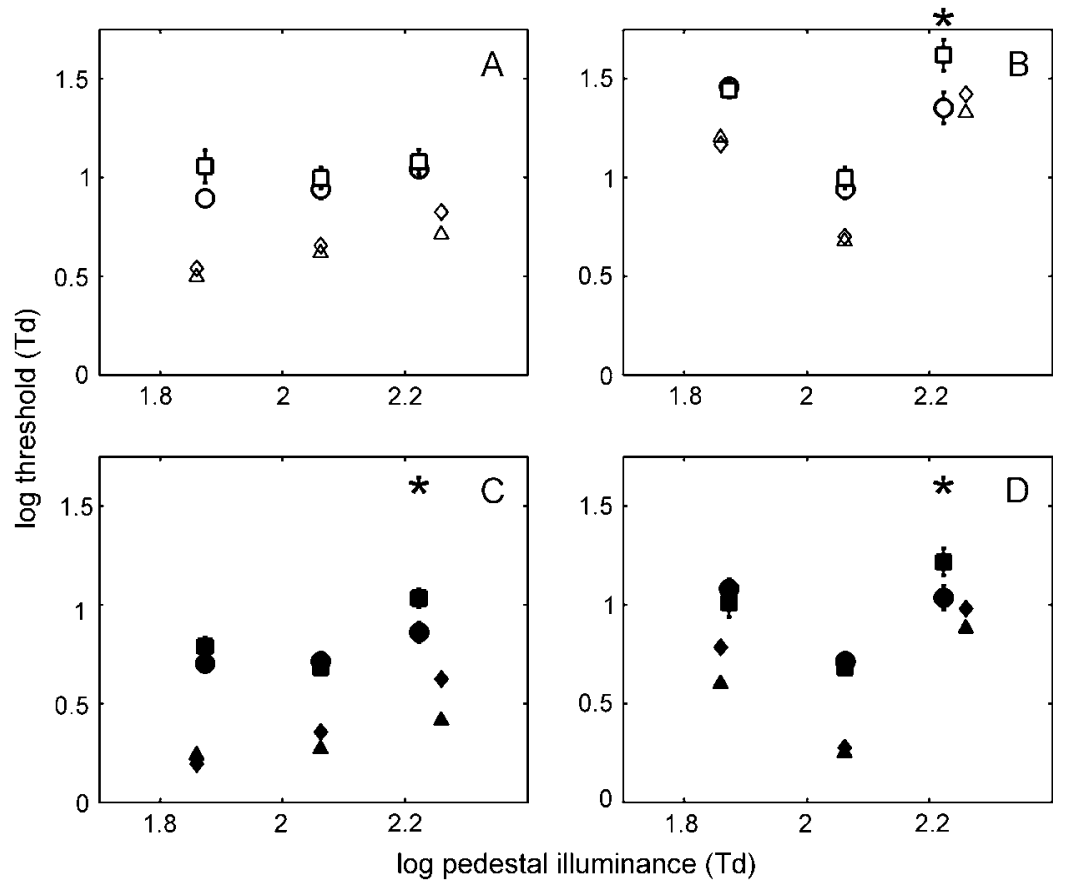

On p. 473, column 1, the third sentence in the second paragraph under the heading Effects of stimulus duration should read as follows:

"The mean Tc-estimates for their two observers were $33.5 \mathrm{~ms}$ for SPP and $49 \mathrm{~ms}$ for PPP, compared with 26.3 (SPP) versus 38.4 (PPP) for our controls." 